\title{
The use of soil electrical resistivity to monitor plant and soil water relationships in vineyards
}

\author{
L. Brillante ${ }^{1}$, O. Mathieu ${ }^{1}$, B. Bois ${ }^{1,2}$, C. van Leeuwen ${ }^{3}$, and J. Lévêque ${ }^{1}$ \\ ${ }^{1}$ UMR CNRS 6282 Biogéosciences, Université de Bourgogne, 6 Boulevard Gabriel, 21000 Dijon, France \\ ${ }^{2}$ Institut Universitaire de la Vigne et du Vin “Jules Guyot”, Rue Claude Laudrey, BP 27877, \\ 21078 Dijon, France \\ ${ }^{3}$ Bordeaux Sciences Agro, ISVV, Ecophysiology and Functional Genomics of Grapevines, UMR 1287, \\ Université de Bordeaux, 33140 Villenave d'Ornon, France \\ Correspondence to: L. Brillante (brillanteluca@live.it)
}

Received: 13 October 2014 - Published in SOIL Discuss.: 29 October 2014

Revised: 26 February 2015 - Accepted: 27 February 2015 - Published: 17 March 2015

\begin{abstract}
Soil water availability deeply affects plant physiology. In viticulture it is considered a major contributor to the "terroir" effect. The assessment of soil water in field conditions is a difficult task, especially over large surfaces. New techniques are therefore required in order to better explore variations of soil water content in space and time with low disturbance and with great precision. Electrical resistivity tomography (ERT) meets these requirements for applications in plant sciences, agriculture and ecology. In this paper, possible techniques to develop models that allow the use of ERT to spatialise soil water available to plants are reviewed. An application of soil water monitoring using ERT in a grapevine plot in Burgundy (north-east France) during the vintage 2013 is presented. We observed the lateral heterogeneity of ERT-derived fraction of transpirable soil water (FTSW) variations, and differences in water uptake depend on grapevine water status (leaf water potentials measured both at predawn and at solar noon and contemporary to ERT monitoring). Active zones in soils for water movements were identified. The use of ERT in ecophysiological studies, with parallel monitoring of plant water status, is still rare. These methods are promising because they have the potential to reveal a hidden part of a major function of plant development: the capacity to extract water from the soil.
\end{abstract}

\section{Introduction}

In viticulture and oenology it is acknowledged that the natural environment has a major impact on the yield and vegetative growth of grapevines and therefore on the sensory attributes of the final product. This link between the characteristics of a wine and its origin is called the "terroir" effect (van Leeuwen and Seguin, 2006). It has been studied on a scientific basis since the 1960s (Seguin, 1969). This relationship is not mediated through the effect of particular soil minerals or flavour compounds, although the popular wine press often erroneously describes it thus (van Leeuwen and Seguin, 2006). The terroir effect must be sought in interactions at the ecosystem level. Major factors in the terroir effect are the supplies of water and nitrogen (van Leeuwen, 2010). Water and nitro- gen are major drivers of vine physiology at the whole-plant level. This paper focuses on soil and vine water relationships.

Soil is not a homogeneous medium, and is therefore not explored by roots in a homogeneous way. Hence, during drought, soil cannot dehydrate in a homogeneous way. It is surprising that such evidence is often neglected, and that available soil water capacity is generally considered a soil characteristic, independent of the plant. The highly variable spatio-temporal distribution of wet and dry zones in soils has profound physiological implications for plants. Indeed, while chemical and hydraulic root signals are produced in moderately dry soil regions, the part of roots in wet soil regions ensures the supply of water and therefore transpiration and photosynthetic activity. Partial root zone drying (PRD) is an irrigation concept based on this knowledge (Dry et al., 1996; 
Loveys et al., 2000; Stoll et al., 2000). It maintains reasonably high yields because vines pick up water from the wet soil zones, while quality is high because roots produce $\mathrm{Ab}$ scisic Acid (ABA) in the dry zones of the soil profile. In natural conditions, such spatial soil water heterogeneity can also be found. The magnitude of such variations in soil moisture and their impact on vine physiology has rarely been studied (one of the few being Bauerle et al., 2008). Soil moisture spatial variations might play a key role in the terroir effect. In a recent review, Schultz and Stoll (2010) remarked that soil water (SW) monitoring is a challenging task because root distribution is generally unknown and it is therefore difficult to understand how much water is effectively absorbed in each soil layer.

The reason why such spatial variations in soil water availability have rarely been considered is that, at present, soil water measurements are generally obtained with in-soil devices such as time domain reflectometers (TDR), which can be difficult to use in field conditions. Furthermore, these devices only measure a very small volume of the soil, and even when the number of probes is increased, no information is generally obtained about the lateral variation of SW and only a vertical soil moisture profile can be established. In addition, the number of such devices cannot be increased indefinitely without major perturbations of the system and incurring prohibitive costs. Geophysical imaging techniques, which are rapid, cost-effective and cause only low perturbation of the soil, have recently been proposed as a good proxy for the spatialisation of soil water measurements (Michot et al., 2003; Beff et al., 2013; Garré et al., 2011, to name but a few). As the technique is recent and a generalised method does not exist, there have been no reviews on the possible approaches to spatially measure soil water and its availability through these geophysical techniques, especially those based on electrical resistivity (ER), which are the most promising.

Vineyards are being studied, within an interdisciplinary view of the soil system (Brevik et al., 2015), due to the high erosion rates (Novara et al., 2011; Lieskovský and Kenderessy, 2014; Martínez-Casasnovas et al., 2013), their special man-made landforms (Tarolli et al., 2015) and pollution (Fernández-Calviño et al., 2013; Novara et al., 2013; ParrasAlcántara et al., 2013). This article concentrates on soil water relationships in vineyards and will review the use of ERT to spatially measure soil water and its availability to plants.

First, the grapevine physiological response to drought will be briefly reviewed, with special regard to plant and soil relationships, as well as soil properties that affect plant water status. Then, the concept of soil water availability to plants will be discussed. Finally, the contribution of geophysical methods, and in particular ER, to the study of plant and soil water relationships in vineyards will be discussed. These tools are very promising for the quantification and visualisation of plant and soil water relationships.

\section{Part 1: A review about the use of ERT to spatially quantify soil water and its availability to plants}

\section{Plant and soil water relationships in terroir}

The effect of water on fruit production has received great interest because it directly affects both the quantity and quality of the final product. Water deficits have a physiological impact at the whole-plant level. The need to acquire knowledge on plant-soil-atmosphere water relationships is further increased by the current context of global warming. A number of studies have therefore flourished on the subject in recent years and have shown that, in addition to trees, grapevines can now be considered as model plants from both physiological and molecular points of view. Among the reasons for such success that can be mentioned here are the great progress made in grapevine genomics (Jaillon et al., 2007) and the long history of ecophysiological research for this plant. A complete physiological and molecular update can be found in Lovisolo et al. (2010). In this section we will provide only a brief overview of water relationships between plants and soils and their effects on terroir.

In grapevine a moderate water deficit reduces berry size and increases technological quality (higher sugar levels and lower acidity, for example). The reason is that the vegetative and reproductive organs are competing sinks for carbohydrates produced by photosynthesis. Apexes are the most important sinks when fruits are not present. When fruits develop, they become progressively more important sinks for carbohydrates. During water stress, apexes reduce and then stop their growth, but the reduction in the vegetative growth varies across vegetative organs and physiological processes (Pellegrino et al., 2005a). If shoot growth stops before veraison, there is no competition for carbohydrates between fruits and apexes during ripening. Red wines benefit from a moderate water deficit, while sparkling or white wines do not, nor table grapes (Sadras and Schultz, 2012). Soils favourable to the installation of a moderate water deficit during the summer, which are generally well suited to the production of high-quality red wines, have been described in France (Seguin, 1975; Choné et al., 2001a; van Leeuwen et al., 2009), Italy (Storchi et al., 2005; Tomasi et al., 2013), Hungary (Zsófi et al., 2009), the USA (Chapman et al., 2005) and in many other regions in the world. Research into the effect of water deficit on the quality of white wines is rare, but one such study was performed by des Gachons et al. (2005). The effect of water deficit on grape quality potential can be negative, because it causes an increase in phenolic compounds, which is not considered favourable for the quality of white wine (Sadras and Schultz, 2012). White wine also needs a certain level of acidity, which is rapidly degraded during water deficit (Ollat et al., 2002).

The amount of plant-available water in soils varies according to soil characteristics, such as soil texture, amount of organic matter and gravel content. Soil characteristics also 
affect the absorption process and have a direct physiological effect on plants. When the texture of the soil is fine, the soil matrix potential is low because of greater forces retaining water in capillary pores and at the surface of clay minerals. Therefore, the plant water potential must be more negative to allow absorption, even if soil volumetric water content is higher in fine-textured soils compared to sandy soils. Indeed, at the wilting point, the soil volumetric water content of fine-textured soil is always higher than that of coarsetextured soils (Kramer and Boyer, 1995). Water in macroand meso-pores is generally more easily available to plants, but it is also more mobile, as it is not retained by capillary forces. Sandy soils have higher macro- and meso-porosity than clayey soils, and the available water tends to be highly variable in time. Contact between roots and soil, which is necessary for absorption, is favoured in fine-textured soils and more difficult in coarse-textured soils, as well as in soils rich in gravels. These parameters influencing soil water potential and water absorption by vines have an important effect on the terroir effect, which is probably indirect and mediated by the physiological adaptations of vines to the surrounding environment (van Leeuwen, 2010). In Bordeaux vineyards, wines produced on clayey soils, where the soil matrix potential is lower, are higher in anthocyanin content than those produced on sandy soils (van Leeuwen et al., 2004). Grapes also ripen faster on clayey soils. In Tuscany, moderately saline soils have been shown to produce the best wines (as evaluated by a sensory panel) even if water is not limited, probably because the lower osmotic potential induces a moderate water deficit, as measured by $\delta^{13} \mathrm{C}$ (Costantini et al., 2009, 2010). Soil texture modifies the plant's response to drought, as shown by Tramontini et al. (2012), who studied the effect of texture on grapevine physiology in neighbouring soils during the same vintage. They observed that gravel soils limited stomatal conductance and predawn water potential more than clayey and sandy soils. In sandy soils, stomatal conductance was highly variable, while it was less in clayey soil. On gravel soils, stomatal conductance was constantly low, independent of the level of water stress. Some authors have attributed the reported physiological differences observed in various soils to differences in root-shoot signalling mediated by ABA (Lovisolo et al., 2010; Ferrandino and Lovisolo, 2014). The water-holding capacity of a soil varies with soil depth. In deeper soils, vine vigour is higher and phenology is delayed (Bodin and Morlat, 2006). Soil depth can also have a direct effect on plant physiology, independent of the water amount, which is known as the bonsai effect (Passioura, 2002). However, the influence of such physiological modifications in field conditions should be further investigated.

With increasingly dry soil conditions, the root/shoot biomass ratio increases (Dry et al., 2000; Hsiao and Xu, 2000). While root growth continues in the most humid soil layers (Bauerle et al., 2008), generally located at greater depths, shoot growth is quickly inhibited by water deficit (Schultz and Matthews, 1988; Lebon et al., 2006). The ex- ploitation of soil water tends to be as complete as possible. Indeed, the use of lateral resources plays a very important role during drought periods (Bauerle et al., 2008). Plants can also lose water during the absorption process at root level. This process is called hydraulic lift, i.e. water redistribution through plant roots from wet to dry soil layers. The amount of water involved can be extremely significant (2-154\%), and the movement of water has been documented in every direction, including lateral transfer (Smart et al., 2005). The phenomenon has several physiological and environmental implications: it increases the survival of roots and maintains rootsoil contact in the more easily drying part of the soil, moistens nutrients in the shallower soil layers, and keeps fine roots alive in this part of the soil (Neumann and Cardon, 2012; Prieto et al., 2012).

\section{Assessing the soil water availability to plants}

The available water capacity of a soil (also called soil water holding capacity, SWHC) has been defined as the difference between two limits of soil water content. The upper limit is the volumetric soil water content at field capacity (the maximum amount of soil water, excluding free water, that a soil is able to store in the root zone), while the lower limit is the volumetric soil water content at the permanent wilting point (the amount below which water is so strongly retained that plants are unable to absorb it). Field capacity corresponds to a soil potential $-0.33 \mathrm{kPa}(\mathrm{pF}=2.45)$, while the permanent wilting point has been defined at $-15 \mathrm{kPa}(\mathrm{pF}=4.2)$ (Richards and Weaver, 1944). The concept of plant available soil water capacity, in the form described here, was first introduced by Veihmeyer and Hendrickson (1950). Its simplicity helped to popularise it for irrigation purposes, but it is far from being unanimously accepted in the scientific community. It has been argued that the definition of the two extremes lacks a universal physical basis (Hillel, 1998), and also that water cannot be considered equally available in the expected range because availability decreases as the soil dries out and soil water potential decreases (Richards and Wadleigh, 1952). Furthermore, it is obvious that water availability to plants cannot be assessed without considering the plant. Roots are not uniformly distributed in the soil, water availability is heterogeneous in space and time, and such heterogeneity affects plant physiology at the whole-plant level. Finally it has been observed that plants, including grapevines (Costantini et al., 2009), can absorb water at lower levels than the theoretical wilting point (i.e. $-15 \mathrm{kPa}$ ). It is worth noting that Veihmeyer and Hendrickson (1950) already reported a similar observation for plants grown in containers. These observations cannot be discounted and have to be taken into account both for irrigation scheduling and for ecophysiological research.

One possible but only partial solution is the concept of total transpirable soil water (TTSW). This approach seeks to include root distribution in the assessment of soil water 
availability for plants (because root absorption is the first cause of water content variation in soils) and also to evaluate soil water capacity on the basis of the physiological response of plants. TTSW is defined as the difference between soil water at field capacity and soil water measured when plants are no longer able to extract water from the soil, which depends on the plant species. Both limits are directly estimated in the field, and not in the laboratory, by moisture release curves. The idea was first advanced by Ritchie (1981) and then successfully experimented with both in herbaceous crops (Lacape et al., 1998; Lecoeur and Guilioni, 1998; Guilioni and Lhomme, 2006, to name but a few) and in woody species (Sinclair et al., 2005; Lu et al., 2010, to name but a few). In grapevines the concept has been used in the most recently developed water balance model (Lebon et al., 2003; Pellegrino et al., 2006; Celette et al., 2010). Water balance modelling is an interesting approach to assess vine water status in both irrigated and non-irrigated vineyards, especially when coupled to plant-based measurements (van Leeuwen et al., 2010). Soil moisture can be difficult to measure in field conditions because the grapevine is a deep-rooting species, often grown on soils rich in gravels. Hence, measuring soil water potential with tensiometers, or soil water content using time domain reflectometry (TDR) or neutron moisture probes, can be difficult or even impossible to implement. Furthermore, these devices measure only a very small volume of soil, and even when the measurement is replicated by increasing the number of probes, no information is generally obtained about the lateral variation of the TTSW. Only a vertical soil moisture profile can be established. In addition, multiplying the number of such devices can lead to major perturbations of the system and prohibitive costs. The estimation of TTSW with such devices depends greatly on the position of access tubes or probes and can therefore yield misleading information. Geophysical imaging measurements such as electrical resistivity provide visual quantification of soil water content in two or three dimensions and assess its variations over time. Electrical resistivity is therefore a powerful tool to study soil water relationships at high spatial and temporal resolution.

\section{Electrical imaging of the soil water}

Applications of geophysical imaging techniques, and specifically electrically based techniques, have been tested and reviewed in hydrology (Robinson et al., 2008), ecology (Jayawickreme et al., 2014), plant science (Attia Al Hagrey, 2007), soil sciences and agronomy (Samouelian et al., 2005, which also reviews the basic principles). They offer promising perspectives in agronomy, for both production and research. The main techniques are based on the direct or indirect measurement of electrical resistivity (or of its opposite, electrical conductivity), such as electrical resistivity tomography (ERT, or electrical resistivity imaging, ERI) and electromagnetic induction (EMI). Measurements can also be recorded with mobile devices, and several commercial sensors have been developed to assist in soil mapping. The success of electrical resistivity is based on its sensitivity to soil properties, including water (Friedman, 2005; Hadzick et al., 2011; Brillante et al., 2014a). It can be implemented for many purposes, like soil texture mapping (Triantafilis and Lesch, 2005); assessment of coarse element content in soils (Tetegan et al., 2012); the study of soil structure and compaction (Besson et al., 2004), soil hydraulic conductivity (Doussan and Ruy, 2009), and soil horizonation (Tabbagh et al., 2000); assessment of the effect of different tillage systems (Basso et al., 2010); map root distribution and quantification of biomass (Amato et al., 2008, 2009; Rossi et al., 2011) and absorption (Srayeddin and Doussan, 2009); agricultural management, especially in precision agriculture (Jaynes et al., 2005; Lesch et al., 2005; Corwin and Lesch, 2005; Andrenelli et al., 2013; André et al., 2012); and in the evaluation of soil volume wetness and transpirable soil water both at the plot scale (Michot et al., 2003; Attia Al Hagrey, 2007; Werban et al., 2008; Garré et al., 2011, 2013; Brillante et al., 2014a, to name but a few) and at the field scale (Besson et al., 2010), with interesting perspectives for applications in plant ecophysiology.

\subsection{Acquiring data}

The relationship between ER and SW has been observed in many studies, by many authors and in many different settings (see Sect. 4.3). It is dependant on soil characteristics and is therefore site-specific. Hence, in order to use ER to monitor soil water it is necessary to perform a calibration, which can be carried out in the field or in the laboratory. The following section will review and compare the procedures used to acquire data to explore the relationship between ER and SW. Modelling details will be described, but the technical and practical aspects of ERT measurements will not be discussed (see the tutorial provided by Loke, 2014).

\subsubsection{Laboratory methods}

Data for successful modelling of the ER-SW relationship can be acquired with either laboratory or field calibration. Laboratory practices ensure tight control over all the environmental parameters and therefore make it possible to develop equations for the complete range of moisture conditions in a given soil in a fast and easy way. Different methods of sample analysis are reported in the literature, from cylindrical undisturbed soil cores (Michot et al., 2003; Michot, 2003) to repacked samples in boxes (Hadzick et al., 2011). The validity of calibration developed in the laboratory for field applications is a matter of debate today, especially when the soil structure is disturbed during sampling. Indeed, soil structure, and especially its porosity, greatly affects soil bulk resistivity (Archie, 1942, and derived models); therefore Friedman (2005) remarked that field application of calibration obtained 
with repacked samples should be avoided because of the possibility of large systematic errors. On the other hand, Nadler (1991) observed that ER-SW relationships were stable, whether measured on "field", "packed" or "severely disturbed samples". Soil structure is not the only problem. Michot et al. (2003) used both laboratory (measuring the resistivity of cylindrical soil cores) and field methods (with the 4P method, described hereafter). They had to discard the first method because the saturation water conductivity of the cylindrical soil cores was different from the conductivity of the soil solution. In addition, they noticed great variability in the resistivity values obtained for different volumes of soil, for the same soil moisture content: the higher the volume of the soil core, the higher the electrical resistivity.

\subsubsection{Field methods}

Field methods permit calibrations specifically adapted to the local context. They are more difficult to implement and the control over the environment is lower than for laboratory methods. In field conditions, it can take a long period of time to obtain a variation in soil water content large enough to fit the model, particularly in deeper soil layers, except for irrigated vineyards located in dry regions. Different methods have been used to examine SW-ER relationships in the field, using electrical resistivity, whether inverted or not. Two methods can be used to measure the bulk ER (i.e. not inverted) of a soil in undisturbed conditions and then to explore ER-SW relationships. The first is the 4P method (principles and an example of application are provided in Michot et al., 2003). This method uses four electrodes inserted perpendicularly to the soil profile in a trench. The major part of each electrode is isolated, except the end, to ensure a punctiform contact with the soil $(1-2 \mathrm{~cm}$, or more in stony soils). Because the soil surrounds the electrodes in all directions and current propagation is not limited by the air, as is the case when electrodes are at the soil surface, the function that allows the measurement of the potential difference, $\Delta V$, uses $4 \pi$ instead of $2 \pi$. The second technique, which is easier to implement, uses the electrical conductivity given by TDR probes to fit the relationship between ER and SW (an example is in Beff et al., 2013). If the TDR device is combined with a datalogger, a large amount of data may be acquired easily, rapidly and efficiently.

When inverted electrical resistivity is used, the inversion uses a grid with the spatial resolution that best fits the soil water measurements. The cells corresponding to the soil layer where soil water measurements are available are selected, and their ER is laterally averaged. The final data that will be used for the spatialisation and imaging in ERT are used to fit the relationships (an example of the procedure is provided in Brillante et al., 2014a). The drawback of this approach is that the inversion process, whether for the ERT technique or for any other imaging technique, only yields estimated values of ER (there is no single solution). The true value approached by inversion is the bulk ER data of a specific region of soil. The bulk ER data would be the most accurate choice, but they are more complicated to obtain because the device used for measuring has to be inserted in the specific region of interest, while with inversion the device can generally be at the soil surface. An advantage of the use of inverted ER is that a greater amount of data can be acquired, therefore providing greater spatial coverage, both vertically and laterally. In addition, Brillante et al. (unpublished data) tested both possibilities, and concluded that if the inversion process converges with a low associated error (lower than $5 \%$ ), then the difference between inverted ER and bulk ER is low enough to justify the use of inverted data. The iteration to select and fit the model also has to be defined. One possibility is to use the iteration with the best performances in the relationship with $\mathrm{SW}$; another is to use the iteration with the lowest error (as measured by RMSE, and lower than $5 \%$ ).

\subsection{Temperature correction}

Electrical current in soils is mainly electrolytic, i.e. based on the displacement of ions in pore water. The electrical resistivity of soil therefore depends on the amount of water in the pores and its concentration in electrolytes. The ER decreases with a decrease in soil water content (Samouelian et al., 2005). However, the electrical resistivity is also dependent on other soil characteristics, such as the amount of gravels and clay, salinity and temperature, the latter of which because of kinetic effects on ion mobility in pore water. Before fitting any relationship between ER and soil water content, it is important to adapt the ER to the reference temperature of $25^{\circ} \mathrm{C}$ (Samouelian et al., 2005). A linear correction equation is generally used to increase (or reduce) ER by a factor $\alpha$ if soil temperature is higher (or lower) than the reference temperature (Campbell et al., 1948). The value of the correction factor is approximately equal to $2 \%$ (in the literature, the factor varies from $1.9 \%$ in Amente et al., 2000, to $2.5 \%$ in Brunet et al., 2010). It has also been observed that the $\alpha$ factor can vary slightly for a given soil depending on its temperature (Illiceto, 1969). Although some studies have neglected this correction (in particular when temperature variations are low), its use should be considered good practice (Brevik et al., 2004; Nijland et al., 2010).

\subsection{Modelling of relationship between ER and SW}

The relationships between ER and SW have been investigated since the 1940s, initially for petroleum research and then in geological contexts (Archie, 1942). Soil ER is dependant on soil properties other than water, such as gravel content, texture class, salinity and temperature (as reviewed in Samouelian et al., 2005). Hence, a unique relationship for an entire soil profile is possible only for homogeneous soils. Examples can be found in Bernard-Ubertosi et al. (2009), Brunet et al. (2010) and Brillante et al. (2014a). If the soil 
is heterogeneous, this has to be taken into account in the relationship. One possible solution is to fit specific relationships for each soil layer (see Michot et al., 2003; Beff et al., 2013; Garré et al., 2011, among others). This method is efficient when SW probes are fixed in the soil. The fitting of many individual relationships for a number of thin and regularly spaced soil layers (for example, every $0.1 \mathrm{~m}$ in Brillante et al., 2014a) can be accurate when soil water is measured by probes inserted in access tubes. The separation of data between the soil surface and the deeper soil layers also improves the fit (Hadzick et al., 2011). Another solution is to include soil properties in the model to used to develop pedotransfer functions (Hadzick et al., 2011; Brillante et al., 2014a). Many authors have developed semi-empirical geophysical models to describe the relationships and investigate the main soil factors involved. Other authors have developed purely empirically relationships. In the following sections, different methods used to spatialise SW by ER are reviewed in two groups: petro-physical models and experimental calibrations.

\subsubsection{Petro-physical models}

The first petro-physical model linking ER to SW was proposed by Archie (1942) and is shown in Eq. (1) in terms of electrical resistivity:

$\rho=\frac{a}{\phi^{m} \theta^{n} \sigma_{w}}$,

where $\rho$ is the electrical resistivity of the fluid-saturated rock, $\phi$ denotes the porosity, $\sigma_{w}$ represent the electrical conductivity of the brine, $\theta$ is the brine saturation, $m$ is the cementation exponent, $n$ the saturation exponent and $a$ is the tortuosity factor. It was developed in pure sand without any clay and can be useful for coarse-grained soil with limited clay content (examples of applications are given in Attia Al Hagrey, 2007; Brunet et al., 2010). Indeed, clays can have a direct effect on soil resistivity because clay minerals are electrically charged and can directly conduct electric current at their surface. The model developed by Waxman and Smits (1968) was based on the Archie model, with the inclusion of a term accounting for the cation exchange capacity (CEC) of the medium. Like the Archie model, the Waxman and Smits model was also developed for geological applications, but it has been successfully applied in soil contexts (Garré et al., 2011). Other modifications of the Archie law have been proposed by other authors (Revil et al., 1998, 2007; Linde et al., 2006; Shah and Singh, 2005), often with increasing complexity in order to better capture the details of the electrical flow in geological contexts. Many of these petro-physical models were tested, in a laboratory experiment, for application on loamy soils by Laloy et al. (2011). The Archie law has been largely applied because of its simplicity (Frohlich and Parke, 1989), as has the Waxman and Smits model, the latter especially in its simplified form (as in Garré et al., 2011; Beff et al., 2013). The generalised form of Archie's law (proposed by Shah and Singh, 2005, with an interesting application in Schwartz et al., 2008) appears to be a valid alternative when the soil contains clay and the conductivity of the soil matrix cannot be neglected.

The use of such petro-physical models is interesting from a geophysical perspective. They allow for comparison with other studies, as the estimated parameters can be reused in similar contexts. They also allow for further understanding of the electrical resistivity of soils. However, in some situations, there is no consensus about the meaning of some parameters in the models, which may have been included only with the aim of improving the fit (e.g. as the $a$ coefficients in the modified Archie law by Winsauer et al., 1952). Moreover, and particularly for the most useful models, the factors influencing the ER-SW relationships are loosely compressed into a few global parameters (as in the simplified Waxman and Smits models), meaning that their precise interpretation remains possible, although it is more difficult (Garré et al., 2011).

\subsubsection{Experimental calibrations}

The use of a petro-physical model is not the only way to predict soil water content by ER. It is also possible to use a direct empirical calibration, by regression analysis, and with parallel measurements of the volumetric soil water content. This can be the most direct approach if the aim is merely to use ER as an ancillary variable to spatialise SW. This technique has an accuracy that is comparable to the application of a petro-physical model, and it has successfully been used by many authors (among others Michot et al., 2003; Calamita et al., 2012; Brillante et al., 2014a). A linear regression analysis was suggested by Gupta and Hanks (1972). However, the relationship between SW and ER appears linear only when considering a limited range of variations of these variables. When looking at the data collected from different studies by Calamita et al. (2012), it appears obvious that the global relationship is not linear (as in all petro-physical models previously reviewed). Some adjustments are therefore needed in order to account for the lack of linearity (Calamita et al., 2012, and Brillante et al., 2014a, reviewed some possibilities of adjustment). Alternatively, non-linear regression techniques have also been used. Extrapolation (i.e. forecasting outside the observed range of data) should be avoided because, in this type of calibration, only the form of relationship relative to the observed data is modelled. Once the relationship has been established, it is applied to transform inverted ER data obtained with ERT method to spatialise the soil water content.

Pedotransfer functions, such the ones typically used in SWHC estimation, are currently being developed. The aim is to estimate SW, available soil water (ASW), fraction of transpirable soil water (FTSW) on the basis of ERT, and a few selected soil properties (Brillante et al., 2014a) in order 
to allow a wider use of the technique without the necessary process of calibration and modelling, which is currently the most time-consuming part of the work. Because of the easy application of these experimental functions, it can be worth comparing them to the other methods previously reviewed.

\section{Part 2: Applying the electrical resistivity to monitor the fraction of transpirable soil water, in relation to grapevine water potentials - a case study}

\section{Material and methods}

\subsection{Experimental site}

The results presented in this study are derived from data collected over 2 years (2012-2013) in an experimental plot located in a commercial vineyard (Domaine Louis Latour, Aloxe-Corton, Burgundy) in France. Each plot is a $7 \mathrm{~m} \times 7 \mathrm{~m}$ area composed of 49 grapevines (Vitis vinifera, L.), cultivar Chardonnay B. grafted on the $\mathrm{SO}_{4}$ rootstock (interspecific cross between Vitis riparia Michx. and Vitis berlandieri Planch.). Vines were guyot-pruned and trained in a vertically shoot position trellis system with the first training wire at $0.5 \mathrm{~m}$ and the fruiting cane trimmed at $1.20 \mathrm{~m}$; distance between plants was approximately $0.9 \mathrm{~m}$. Plant position was taken with a differential GPS (DGPS Trimble Geo XH V6, precision $<5-10 \mathrm{~cm}$ ). The soil is a Calcaric Cambisol (Aric, Colluvic, Loamic, Protocalcic) according to the World Reference Base for Soil Resources (IUSS Working Group WRB, 2014), located in a foot-slope positions. The colluvium is mainly composed of fine earth eroded from the soils of the upper part of the slope, but also gravel (20\% in volume in the first metre of the profile). The parent material was a marllimestone series dating from the middle Oxfordian. Figure 1 illustrates the plot location and equipment. Each plot was equipped with three Tecanat ${ }^{\mathrm{TM}}$ access tubes for TDR soil water measurement profiles and with 24 stainless steel electrodes for ERT measurements. Meteorological data were collected from an on-site weather station.

\subsection{FTSW measurement and spatialisation}

In 2012 and 2013, SW was measured weekly from bunch closure to grape maturity (approx. mid-June to mid-September, 28 dates) by TDR (TRIME-T3 IMKO GmbH, Ettlingen, Germany; precision $\pm 2 \%$ ). From SW measurements FTSW data were computed as defined in the work by Pellegrino et al. (2005b). The minimum and maximum $\mathrm{SW}$ values necessary to compute the FTSW were found with a complete search over all available measurements for each depth. Plants reached a minimum value of approximately $-0.4 \mathrm{MPa}$, necessary to approximate the lower bound of FTSW during 2012. On the same days, electrical resistivity measurements were performed using a multichannel resistivity meter (Syscal Junior, Iris Instruments, Orleans, France) with

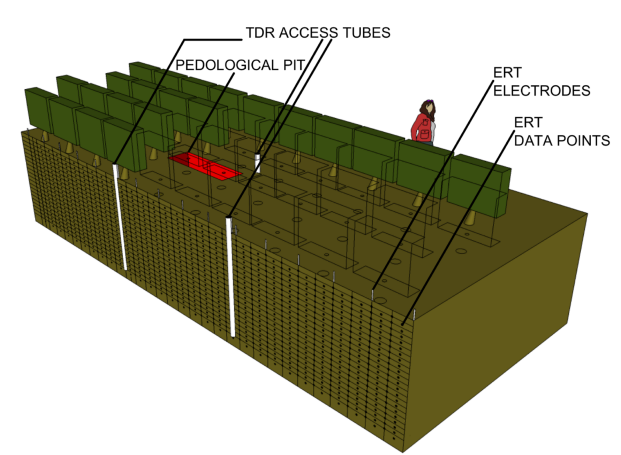

Figure 1. Scheme in 3-D which illustrates the equipment of the experimental plot in the vineyard with devices for hydric and geophysical field-data acquisition. This image has already appeared in Brillante et al. (2014a), courtesy of Elsevier.

24 stainless steel electrodes to generate high-resolution 2-D electrical resistivity images along the vine rows, with pixels of $0.375 \mathrm{~m}$ by $0.1 \mathrm{~m}$. The total length of the geophysical transect was $17.25 \mathrm{~m}$. The centre of the geophysical transect is where the sensitivity of the electrical measurement is higher and the investigation is deeper. Grapevines of the experimental plots where therefore chosen in correspondence of the transect centre (length of the grapevine plots $7 \mathrm{~m}$ ). A pedotransfer function specifically developed in this soil and published in Brillante et al. (2014b) was used to obtain 2-D images of the FTSW. The random forest model used for the pedotransfer function had an RMSE of $17 \%$ in FTSW.

\subsection{Plant physiological measurements}

Predawn leaf $\Psi_{\text {pd }}$ and solar noon stem $\Psi_{\text {stem }}$ water potentials (Choné et al., 2001b) were monitored weekly with a pressure chamber (PMS Instruments Inc., Albany, OR, USA). Eight grapevines were measured for $\Psi_{\text {pd }}$ and 12 for $\Psi_{\text {stem. }}$. Plant water potentials were measured on the same day of soil water and electrical resistivity measurements.

\section{Results and discussion}

Following the procedure described here above, the maps in Fig. 2 were obtained. They show the variations in the FTSW in a vineyard soil during the last year of the 2 years of measurement (2013). In parallel the evolution of grapevine leaf water potential is provided, measured both at the time of maximum rehydration (red line, predawn leaf water potential) and at the time of maximum transpiration (blue line, solar noon stem water potential). Rainfall and temperatures are also indicated. At a first glance, maps of FTSW can be somewhat misleading, because even if all pixels are on the same scale (as FTSW is a normalised variable), the numerical relationship between FTSW and ASW varies across pixels. It has to be considered that FTSW maps do not show dry and wet soil regions, but they do show differences in soil water 

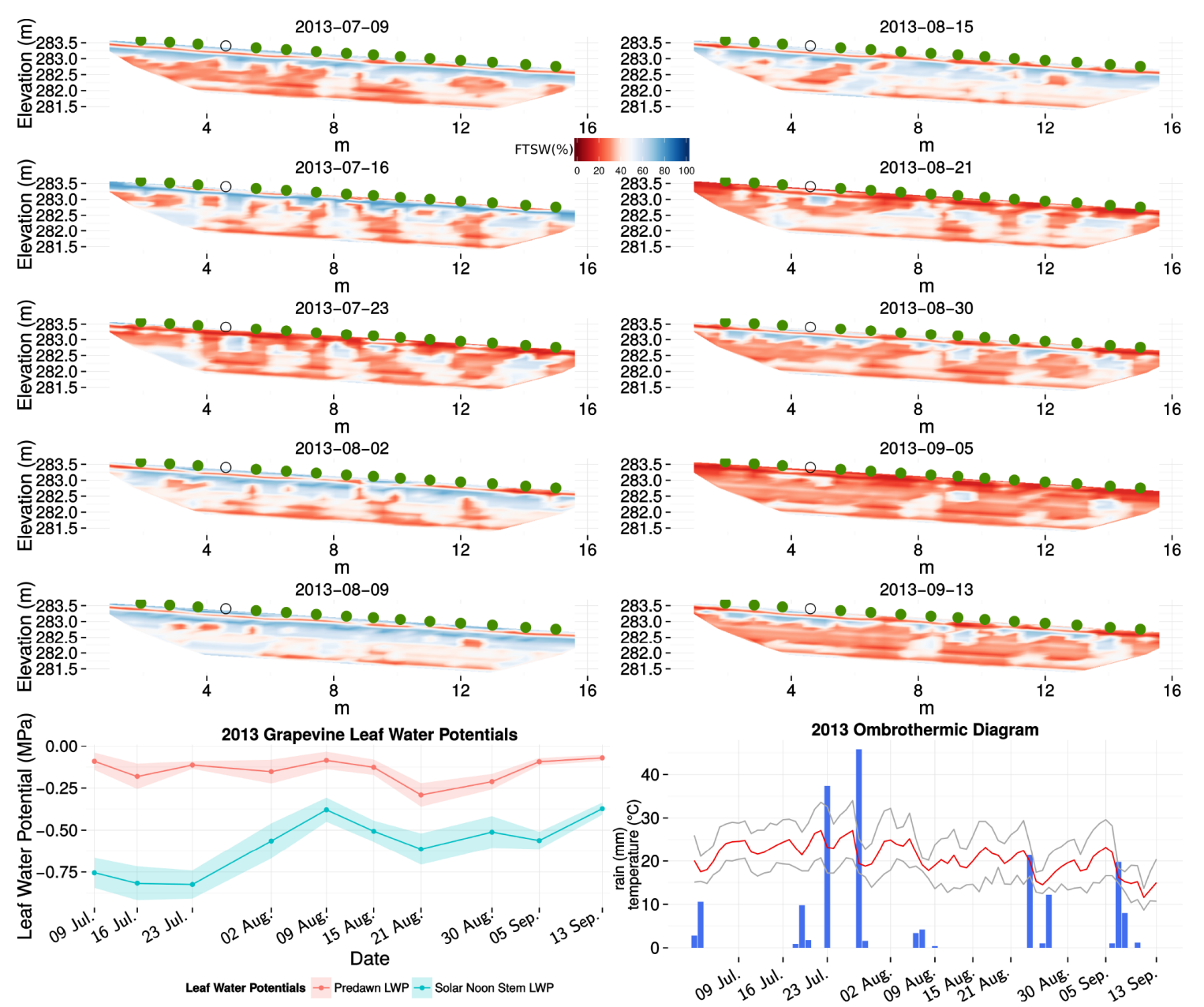

Figure 2. Weekly estimation of the fraction of transpirable soil water (FTSW) in a vineyard soil spatialised in 2-D by electrical resistivity tomography. Green-filled dots represent fully developed plants and empty dots represent very young plants (1 year). The bottom-left panel shows the grapevine water stress variation as measured by leaf water potentials, and the bottom-right panel the ombrothermic diagram of 2013 vintages, temperatures and precipitations.

depletion. Because of the relative scale, the amount of water needed to bring the FTSW of two depleted pixels with the same FTSW to 100 can be different, and these maps cannot be read in this way. Regions of the soil that are only marginally explored by roots, where all the FTSW correspond to $0.01-0.02 \mathrm{~cm}^{3} \mathrm{~cm}^{-3}$ (1-2\%vol.) of SW, very soon reach their extreme low and high values. A low FTSW value is not necessarily the sign of greater root absorption but is primarily the sign of the depletion of the water reservoir. However such confusion disappears when looking at the map time series as a whole.

In Fig. 2 it appears that the FTSW and grapevine leaf water potentials follow a similar temporal pattern, with alternating phases of depletion and replenishment, even at a weekly scale. The pattern is also obviously related to the amount of rainfall. Soil water tended to deplete throughout the season, but heavy rains replenished the reservoir several times during the season, especially at the end of July and the end of Au- gust. The grapevine water deficit followed the same pattern, even if it never indicated a severe plant water stress, but a moderate one. It is very interesting to observe that the midday $\Psi_{\text {stem }}$ appears to be more sensitive than $\Psi_{\text {pd }}$ to even slight variations in the FTSW, and follows the overall pattern of soil moisture well. This confirms observations by van Leeuwen et al. (2010). Between 0.10 and $0.20 \mathrm{~m}$ depth, a compacted layer shows a singular temporal behaviour, compared to the rest of the shallow soil, with low values of FTSW, even in rewetting phases. This layer is little explored by the root system and can prevent water infiltration. The spatial variation in FTSW is not limited to a vertical gradient, as it also varies laterally, even if the grapevines are planted very densely in this plot $(0.9 \mathrm{~m}$ between plants). Traditional systems used for monitoring soil water (TDR, neutron probes, etc.) can fail to accurately assess the overall amount of the FTSW if the choice of their location is not appropriate and if their position relative to plants is taken into account. 

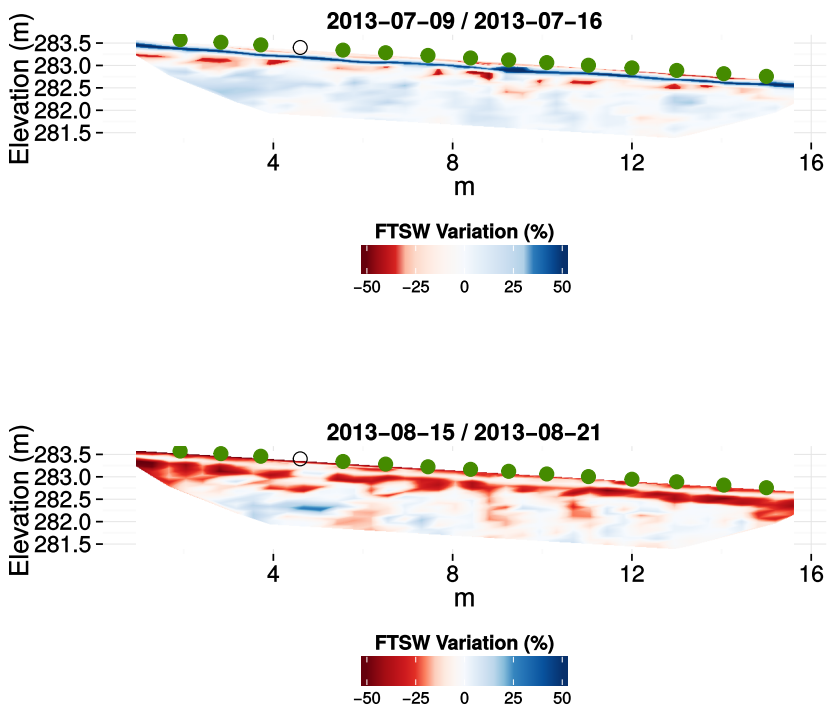

Figure 3. Variations in FTSW between two periods. White colouring is mapped to the error associated with the computation of the difference; further explanation can be found in the text. Green-filled dots represent fully developed plants and empty dots represent very young plants (1 year).

Figure 3 plots the variations of ER between two periods (16-23 July 2013 and 15-21 August 2013), characterised by a steeper reduction in the FTSW compared to other days. These measurements were carried out at the end of the two longest dry periods, with a parallel drop in leaf water potentials. Variation maps, if compared to TDR-based FTSW, may have higher errors than single date maps because of the cumulation of errors when computing the differences between the FTSW for various dates. The colour palette chosen for presenting these maps takes into account the error (as measured by RMSE). White is used for pixels that do not vary, and a gradient red or blue is used once the threshold of RMSE is passed. Hence, when red or blue is used, the difference in FTSW for different dates is significant. When looking at 16 and 23 July and 15 and 21 August in Fig. 2 it appears that the soil globally dries out, but, looking at Fig. 3 , it becomes obvious that these differences are very localised. In July, when the water deficit is still low, the regions of greater variations of FTSW are located at the soil surface. In the map from 21 August, where the water deficit is higher (the predawn leaf water potential lower), greater reduction of FTSW is observed between the grapevines, as well as in deeper layers of the soil. It is also interesting that FTSW variations are reduced for both maps at the location of a young vine. It appears that regions of great variations in FTSW alternate with regions of lower variation. However, the spatial organisation appears dependent on the level of water deficit experienced by the grapevines. On 16 July, the predawn leaf water potential is less negative than on 21 August and, with a lower water deficit, water absorption remains localised at the soil
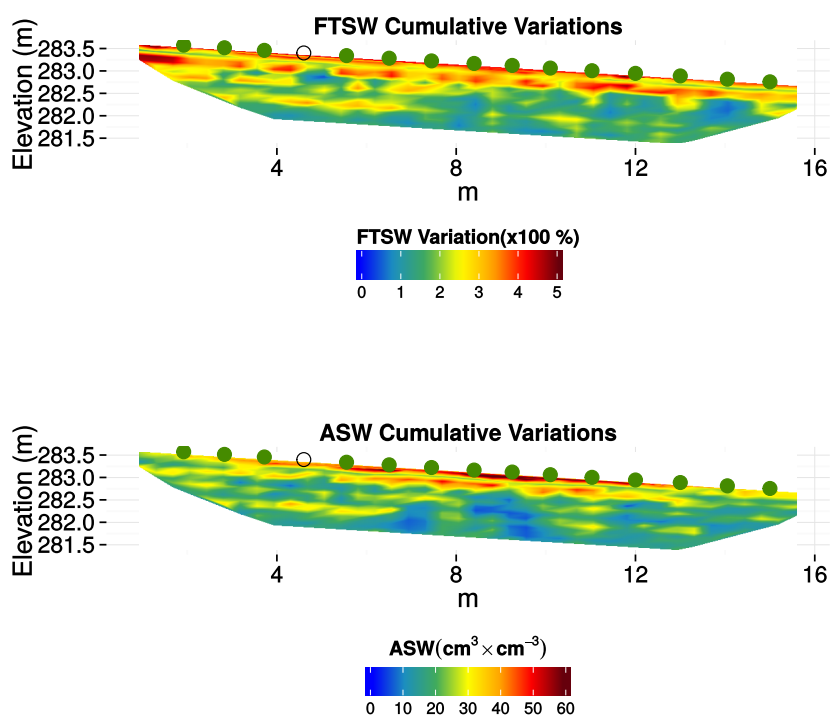

Figure 4. Cumulative variations of FTSW and ASW in a vineyard soil. These were obtained by summing the absolute values of the variations between two successive measurements for these variables (28 measurements). Green-filled dots represent fully developed plants and empty dots represent very young plants (1 year).

surface. Lateral heterogeneity of FTSW is greater than in August. Indeed, in the August map, the soil regions located immediately beneath the grapevines appear to show the greatest FTSW variations, but they also seem to increase the exploitation of water in the area between plants.

Finally, Fig. 4 summarises the spatio-temporal soil water relationships by cumulating the absolute values of all variations observed over 2 years (computed from the 28 dates of measurement) in order to qualitatively detect hotspots in soil for water absorption in relation to the observed water deficit during the monitoring period.

\section{Conclusions}

This paper begins with the role of SW in the terroir to review the current knowledge about soil water availability to plants and its measurement. Specifically, it concentrates on the use of ER for this purpose. Today, ER techniques arouse a great interest among scientists and professionals because they allow for spatial quantification of water in soils in a rapid way and with low perturbation. Generic reviews on electrical resistivity can be found in the literature (a good example is Samouelian et al., 2005), but works centred on the use of ERT to monitor SW were still lacking. This review has tried to be as complete as possible, but evidently some aspects will merit further considerations. As an example, the work does not describe in detail ERT-related technical approaches and their suitability to spatialise and measure SW, such as the use of different arrays, long electrodes or inversion methodologies. Conversely, this work well describes methods and 
modelling approaches to calibrate ER with TDR measurements. However, some of the reported techniques are still in their infancy, such as the use of pedotransfer functions in SW estimation, and therefore their validity will be assessed in time. A case study is presented at the end of the article, with the purpose of showing the technique and to stimulate curiosity in non-expert readers.

In conclusion, we believe that ERT is a technique with a great future in agronomic scenarios, both from a research and production point of view. It will allow for answers to new questions on plant and soil relationships, and it will also open the way to new techniques for water management in agricultural scenarios.

Acknowledgements. This work was funded by the Conseil Régional de Bourgogne and the Bureau Interprofessionnel des Vins de Bourgogne (BIVB). The authors wish to thank Domaine Latour for the access to the vineyard; Carmela Chateau Smith for assistance with English; Sarah De Ciantis, Céline Faivre-Primot, Thomas Marchal and Basile Pauthier for help in laboratory analysis and field-data acquisition. The authors wish also to thank the anonymous reviewers for help in improving the quality of the manuscript.

Edited by: A. Cerdà

\section{References}

Amato, M., Basso, B., Celano, G., Bitella, G., Morelli, G., and Rossi, R.: In situ detection of tree root distribution and biomass by multi-electrode resistivity imaging, Tree Physiology, 28, 1441-1448, 2008.

Amato, M., Bitella, G., Rossi, R., Gómez, J. A., Lovelli, S., and Gomes, J. J. F.: Multi-electrode 3D resistivity imaging of alfalfa root zone, European J. Agronomy, 31, 213-222, doi:10.1016/j.eja.2009.08.005, 2009.

Amente, G., Baker, J., and Reece, C.: Estimation of soil solution electrical conductivity from bulk soil electrical conductivity in sandy soils, Soil Sci. Soc. Am. J., 64, 1931-1939, 2000.

André, F., van Leeuwen, C., Saussez, S., Van Durmen, R., Bogaert, P., Moghadas, D., de Rességuier, L., Delvaux, B., Vereecken, H., and Lambot, S.: High-resolution imaging of a vineyard in south of France using ground-penetrating radar, electromagnetic induction and electrical resistivity tomography, J. Appl. Geophys., 78, 113-122, doi:10.1016/j.jappgeo.2011.08.002, 2012.

Andrenelli, M. C., Magini, S., Pellegrini, S., Perria, R., Vignozzi, N., and Costantini, E. A. C.: The use of the ARPC system to reduce the costs of soil survey for precision viticulture, J. Appl. Geophys., 99, 24-34, doi:10.1016/j.jappgeo.2013.09.012, 2013.

Archie, G. E.: The electrical resistivity log as an aid in determining some reservoir characteristics, Transactions of the AIME, 146, 54-62, 1942.

Attia Al Hagrey, S.: Geophysical imaging of root-zone, trunk, and moisture heterogeneity, J. Exp. Botany, 58, 839-854, doi:10.1093/jxb/er1237, 2007.

Basso, B., Amato, M., Bitella, G., Rossi, R., Kravchenko, A., Sartori, L., Carvahlo, L. M., and Gomes, J.: Two-dimensional spatial and temporal variation of soil physical properties in tillage systems using electrical resistivity tomography, Agronomy J., 102, 440, doi:10.2134/agronj2009.0298, 2010.

Bauerle, T. L., Smart, D. R., Bauerle, W. L., Stockert, C., and Eissenstat, D. M.: Root foraging in response to heterogeneous soil moisture in two grapevines that differ in potential growth rate, New Phytologist, 179, 857-866, doi:10.1111/j.14698137.2008.02489.x, 2008.

Beff, L., Günther, T., Vandoorne, B., Couvreur, V., and Javaux, M.: Three-dimensional monitoring of soil water content in a maize field using Electrical Resistivity Tomography, Hydrol. Earth Syst. Sci., 17, 595-609, doi:10.5194/hess-17-595-2013, 2013.

Bernard-Ubertosi, M., Dudoignon, P., and Pons, Y.: Characterization of structural profiles in clay-rich marsh soils by cone resistance and resistivity measurements, Soil Sci. Soc. Am. J., 73, 46, doi:10.2136/sssaj2007.0347, 2009.

Besson, A., Cousin, I., Samouëlian, A., Boizard, H., and Richard, G.: Structural heterogeneity of the soil tilled layer as characterized by 2D electrical resistivity surveying, Soil Tillage Re., 79, 239-249, doi:10.1016/j.still.2004.07.012, 2004.

Besson, A., Cousin, I., Bourennane, H., Nicoullaud, B., Pasquier, C., Richard, G., Dorigny, A., and King, D.: The spatial and temporal organization of soil water at the field scale as described by electrical resistivity measurements, European J. Soil Sci., 61, 120-132, doi:10.1111/j.1365-2389.2009.01211.x, 2010.

Bodin, F. and Morlat, R.: Characterization of viticultural terroirs using a simple field model based on soil depth I. Validation of the water supply regime, phenology and vine vigour, in the Anjou vineyard (France), Plant Soil, 281, 37-54, doi:10.1007/s11104005-3768-0, 2006.

Brevik, E. C., Fenton, T. E., and Horton, R.: Effect of daily soil temperature fluctuations on soil electrical conductivity as measured with the Geonics EM-38, Precision Agriculture, 5, 145152, 2004.

Brevik, E. C., Cerdà, A., Mataix-Solera, J., Pereg, L., Quinton, J. N., Six, J., and Van Oost, K.: The interdisciplinary nature of SOIL, SOIL, 1, 117-129, doi:10.5194/soil-1-117-2015, 2015.

Brillante, L., Bois, B., Mathieu, O., Bichet, V., Michot, D., and Lévêque, J.: Monitoring soil volume wetness in heterogeneous soils by electrical resistivity. A field-based pedotransfer function, J. Hydrol., 516, 55-66, doi:10.1016/j.jhydrol.2014.01.052, 2014a.

Brillante, L., Bois, B., Mathieu, O., and Leveque, J.: Spatiotemporal analysis of grapevine water behaviour in hillslope vineyards. The example of Corton Hill, Burgundy, in: Xth International Terroir Congress, p. 6, 2014b.

Brunet, P., Clément, R., and Bouvier, C.: Monitoring soil water content and deficit using Electrical Resistivity Tomography (ERT) A case study in the Cevennes area, France, J. Hydrol., 380, 146153, doi:10.1016/j.jhydrol.2009.10.032, 2010.

Calamita, G., Brocca, L., Perrone, A., Piscitelli, S., Lapenna, V., Melone, F., and Moramarco, T.: Electrical resistivity and TDR methods for soil moisture estimation in central Italy test-sites, J. Hydrol., 454-455, 101-112, doi:10.1016/j.jhydrol.2012.06.001, 2012.

Campbell, R. B., Bower, C. A., and Richards, L. A.: Change of electrical conductivity with temperature and the relation of osmotic 
pressure to electrical conductivity and ion concentration for soil extracts, Soil Sci. Soc. Am. Proc., 13, 66-69, 1948.

Celette, F., Ripoche, A., and Gary, C.: WaLIS - A simple model to simulate water partitioning in a crop association: The example of an intercropped vineyard, Agric. Water Manag., 97, 1749-1759, doi:10.1016/j.agwat.2010.06.008, 2010.

Chapman, D. M., Roby, G., Ebeler, S. E., Guinard, J.-X., and Matthews, M. A.: Sensory attributes of Cabernet Sauvignon wines made from vines with different water status, Australian J. Grape Wine Res., 11, 339-347, 2005.

Choné, X., Van Leeuwen, C., Chery, P., and Ribéreau-Gayon, P.: Terroir influence on water status and nitrogen status of nonirrigated cabernet sauvignon (Vitis vinifera). Vegetative development, must and wine composition (Example of a Medoc top estate vineyard, Saint Julien Area, Bordeaux , 1997), South African J. Enology Viticulture, 22, 8-26, 2001a.

Choné, X., van Leeuwen, C., Dubourdieu, D., and Gaudillère, J. P.: Stem water potential is a sensitive indicator of grapevine water status, Annals of Botany, 87, 477-483, doi:10.1006/anbo.2000.1361, 2001b.

Corwin, D. L. and Lesch, S. M.: Characterizing soil spatial variability with apparent soil electrical conductivity, Comput. Electr. Agriculture, 46, 135-152, doi:10.1016/j.compag.2004.11.003, 2005.

Costantini, E. A. C., Pellegrini, S., Bucelli, P., Storchi, P., Vignozzi, N., Barbetti, R., and Campagnolo, S.: Relevance of the Lin's and Host hydropedological models to predict grape yield and wine quality, Hydrol. Earth Syst. Sci., 13, 1635-1648, doi:10.5194/hess-13-1635-2009, 2009.

Costantini, E. A. C., Pellegrini, S., Bucelli, P., Barbetti, R., Campagnolo, S., Storchi, P., Magini, S., and Perria, R.: Mapping suitability for Sangiovese wine by means of $\delta 13 \mathrm{C}$ and geophysical sensors in soils with moderate salinity, European J. Agronomy, 33, 208-217, doi:10.1016/j.eja.2010.05.007, 2010.

des Gachons, C. P., van Leeuwen, C., Tominaga, T., Soyer, J. P., Gaudillère, J. P., and Dubourdieu, D.: Influence of water and nitrogen deficit on fruit ripening and aroma potential of Vitis vinifera L cv Sauvignon blanc in field conditions, J. Sci. Food Agric., 85, 73-85, doi:10.1002/jsfa.1919, 2005.

Doussan, C. and Ruy, S.: Prediction of unsaturated soil hydraulic conductivity with electrical conductivity, Water Resour. Res., 45, 1-12, doi:10.1029/2008WR007309, 2009.

Dry, P., Loveys, B. R., Botting, D., and During, H.: Effects of partial root-zone drying on grapevine vigour, yeld, composition of fruit and use of water, in: Proceedings of the 9th Australian Wine Industry Technical Conference, pp. 126-131, 1996.

Dry, P. R., Loveys, B. R., and During, H.: Partial drying of the rootzone of grape. II. Changes in the pattern of root development, Vitis, 39, 9-12, 2000.

Fernández-Calviño, D., Garrido-Rodríguez, B., López-Periago, J. E., Paradelo, M., and Arias-Estévez, M.: Spatial distribution of copper fractions in a vineyard soil, Land Degradation Develop., 24, 556-563, doi:10.1002/ldr.1150, 2013.

Ferrandino, A. and Lovisolo, C.: Abiotic stress effects on grapevine (Vitis vinifera L.): Focus on abscisic acidmediated consequences on secondary metabolism and berry quality, Environ. Exp. Botany, 103, 138-147, doi:10.1016/j.envexpbot.2013.10.012, 2014.
Friedman, S. P.: Soil properties influencing apparent electrical conductivity: a review, Comput. Electr. Agric., 46, 45-70, doi:10.1016/j.compag.2004.11.001, 2005.

Frohlich, R. K. and Parke, C. D.: The electrical resistivity of the vadose zone - Field Survey, Groundwater, 27, 524-530, 1989.

Garré, S., Javaux, M., Vanderborght, J., Pagès, L., and Vereecken, H.: Three-dimensional electrical resistivity tomography to monitor root zone water dynamics, Vadose Zone J., 10, 412-424, doi:10.2136/vzj2010.0079, 2011.

Garré, S., Coteur, I., Wongleecharoen, C., Kongkaew, T., Diels, J., and Vanderborght, J.: Noninvasive monitoring of soil water dynamics in mixed cropping systems: a case study in ratchaburi province, Thailand, Vadose Zone J., 12, 1-12, doi:10.2136/vzj2012.0129, 2013.

Guilioni, L. and Lhomme, J. P.: Modelling the daily course of capitulum temperature in a sunflower canopy, Agric. For. Meteorol., 138, 258-272, doi:10.1016/j.agrformet.2006.05.010, 2006.

Gupta, S. C. and Hanks, R. J.: Influence of water content on electrical conductivity of the soil, Soil Sci. Soc. Am. Proc., 36, 855857, 1972.

Hadzick, Z. Z., Guber, A. K., Pachepsky, Y. A., and Hill, R. L.: Pedotransfer functions in soil electrical resistivity estimation, Geoderma, 164, 195-202, doi:10.1016/j.geoderma.2011.06.004, 2011.

Hillel, D.: Environmental soil physics, Academic Press, San Diego, CA, 1998.

Hsiao, T. C. and Xu, L. K.: Sensitivity of growth of roots versus leaves to water stress: biophysical analysis and relation to water transport, J. Exp. Botany, 51, 1595-1616, 2000.

Illiceto, V.: Contribution à la prospection géophysique des sites archéologiques, PhD thesis, Université de Paris, 1969.

IUSS Working Group WRB: World reference base for soil resources 2014. International soil classification system for naming soils and creating legends for soil maps, FAO, Rome, world soil edn., 2014.

Jaillon, O., Aury, J.-M., Noel, B., Policriti, A., Clepet, C., Casagrande, A., Choisne, N., Aubourg, S., Vitulo, N., Jubin, C., Vezzi, A., Legeai, F., Hugueney, P., Dasilva, C., Horner, D., Mica, E., Jublot, D., Poulain, J., Bruyère, C., Billault, A., Segurens, B., Gouyvenoux, M., Ugarte, E., Cattonaro, F., Anthouard, V., Vico, V., Del Fabbro, C., Alaux, M., Di Gaspero, G., Dumas, V., Felice, N., Paillard, S., Juman, I., Moroldo, M., Scalabrin, S., Canaguier, A., Le Clainche, I., Malacrida, G., Durand, E., Pesole, G., Laucou, V., Chatelet, P., Merdinoglu, D., Delledonne, M., Pezzotti, M., Lecharny, A., Scarpelli, C., Artiguenave, F., Pè, M. E., Valle, G., Morgante, M., Caboche, M., Adam-Blondon, A.-F., Weissenbach, J., Quétier, F., and Wincker, P.: The grapevine genome sequence suggests ancestral hexaploidization in major angiosperm phyla, Nature, 449, 463467, doi:10.1038/nature06148, 2007.

Jayawickreme, D. H., Jobbágy, E. G., and Jackson, R. B.: Geophysical subsurface imaging for ecological applications, New Phytologist, 201, 1170-1175, 2014.

Jaynes, D. B., Colvin, T. S., and Kaspar, T. C.: Identifying potential soybean management zones from multiyear yield data, Comput. Electronics Agric., 46, 309-327, doi:10.1016/j.compag.2004.11.011, 2005.

Kramer, P. and Boyer, J.: Water relations of plants and soils, Academic Press, San Diego, CA, 1995. 
Lacape, M. J., Wery, J., and Annerose, D. J. M.: Relationships between plant and soil water status in five field-grown cotton (Gossypium hirsutum L .) cultivars, Field Crops Res., 57, 29-43, doi:10.1016/S0378-4290(97)00111-1, 1998.

Laloy, E., Javaux, M., Vanclooster, M., Roisin, C., and Bielders, C. L.: Electrical resistivity in a loamy soil: identification of the appropriate pedo-electrical model, Vadose Zone J., 10, 10231033, doi:10.2136/vzj2010.0095, 2011.

Lebon, E., Dumas, V., Pieri, P., and Schultz, H. R.: Modelling the seasonal dynamics of the soil water balance of vineyards, Functional Plant Biol., 30, 699-710, doi:10.1071/FP02222, 2003.

Lebon, E., Pellegrino, A., Louarn, G., and Lecoeur, J.: Branch development controls leaf area dynamics in grapevine (Vitis vinifera) growing in drying soil, Annals of Botany, 98, 175-185, doi:10.1093/aob/mc1085, 2006.

Lecoeur, J. and Guilioni, L.: Rate of leaf production in response to soil water deficits in field pea, Field Crops Res., 57, 319-328, doi:10.1016/S0378-4290(98)00076-8, 1998.

Lesch, S. M., Corwin, D. L., and Robinson, D. A.: Apparent soil electrical conductivity mapping as an agricultural management tool in arid zone soils, Comput. Electronics Agric., 46, 351-378, doi:10.1016/j.compag.2004.11.007, 2005.

Lieskovský, J. and Kenderessy, P.: Modelling the Effect of Vegetation Cover and Different Tillage Practices on Soil Erosion in Vineyards: a Case Study in Vráble (Slovakia) Using WATEM/SEDEM, Land Degradation Development, 25, 288-296, 2014.

Linde, N., Binley, A., Tryggvason, A., Pedersen, L. B., and Revil, A.: Improved hydrogeophysical characterization using joint inversion of cross-hole electrical resistance and groundpenetrating radar traveltime data, Water Resour. Res., 42, 1-16, doi:10.1029/2006WR005131, 2006.

Loke, M. H.: Tutorial 2-D and 3-D electrical imaging surveys, February, Geotomo Software, 2014.

Loveys, B. R., Dry, P. R., Stoll, M., and Mc Carthy, M. G.: Using plant physiology to improve the water use efficiency of horticultural crops, Acta Horticulturae, 537, 187-197, 2000.

Lovisolo, C., Perrone, I., Carra, A., Ferrandino, A., Flexas, J., Medrano, H., and Schubert, A.: Drought-induced changes in development and function of grapevine (Vitis spp.) organs and in their hydraulic and non-hydraulic interactions at the whole-plant level: a physiological and molecular update, Funct. Plant Biol., 37, 98-116, 2010.

Lu, Y., Equiza, M. A., Deng, X., and Tyree, M. T.: Recovery of Populus tremuloides seedlings following severe drought causing total leaf mortality and extreme stem embolism, Physiol. Plant., 140, 246-257, doi:10.1111/j.1399-3054.2010.01397.x, 2010.

Martínez-Casasnovas, J. A., Ramos, M. C., and Benites, G.: Soil and water assessment tool soil loss simulation at the sub-basin scale in the alt penedès-anoia vineyard region (NE spain) in the 2000s, Land Degradation Develop., published online first, doi:10.1002/ldr.2240, 2013.

Michot, D.: Intérêt de la géophysique de subsurface et de la télédétection multispectrale pour la cartographie des sols et le suivi de leur fonctionnement hydrique à l'échelle intraparcellaire, $\mathrm{PhD}$ thesis, Université Paris, 6, 2003.

Michot, D., Benderitter, Y., Dorigny, A., Nicoullaud, B., King, D., and Tabbagh, A.: Spatial and temporal monitoring of soil water content with an irrigated corn crop cover using surface electri- cal resistivity tomography, Water Resour. Res., 39, 14-1-14-20, doi:10.1029/2002WR001581, 2003.

Nadler, A.: Effect of soil structure on bulk soil electrical conductivity (ECa) using the TDR and 4P techniques, Soil Sci., 152, 199-203, 1991.

Neumann, R. B. and Cardon, Z. G.: The magnitude of hydraulic redistribution by plant roots: a review and synthesis of empirical and modeling studies, New Phytologist, 194, 337-352, doi:10.1111/j.1469-8137.2012.04088.x, 2012.

Nijland, W., van der Meijde, M., Addink, E. A., and de Jong, S. M.: Detection of soil moisture and vegetation water abstraction in a Mediterranean natural area using electrical resistivity tomography, Catena, 81, 209-216, doi:10.1016/j.catena.2010.03.005, 2010.

Novara, A., Gristina, L., Saladino, S. S., Santoro, A., and Cerdà, A.: Soil erosion assessment on tillage and alternative soil managements in a Sicilian vineyard, Soil Tillage Res., 117, 140-147, doi:10.1016/j.still.2011.09.007, 2011.

Novara, A., Gristina, L., Guaitoli, F., Santoro, A., and Cerdà, A.: Managing soil nitrate with cover crops and buffer strips in Sicilian vineyards, Solid Earth, 4, 255-262, doi:10.5194/se-4-2552013, 2013.

Ollat, N., Diakou-Verdin, P., Carde, J. P., Barrieu, F., and Gaudillère, J. P.: Grape berry development: a review, J. Int. Scie. Vigne Vin, 36, 109-131, 2002.

Parras-Alcántara, L., Martín-Carrillo, M., and Lozano-García, B.: Impacts of land use change in soil carbon and nitrogen in a Mediterranean agricultural area (Southern Spain), Solid Earth, 4, 167-177, doi:10.5194/se-4-167-2013, 2013.

Passioura, J. B.: Soil conditions and plant growth, Plant, Cell Environ., 25, 311-318, 2002.

Pellegrino, A., Lebon, E., Simonneau, T., and J, W.: Towards a simple indicator of water stress in grapevine (Vitis vinifera $\mathrm{L}$.) based on the differential sensitivities of vegetative growth components, Aust. J. Grape Wine Res., 11, 306-315, doi:10.1111/j.17550238.2005.tb00030.x, 2005a.

Pellegrino, A., Lebon, E., Voltz, M., and Wery, J.: Relationships between plant and soil water status in vine (Vitis vinifera L.), Plant Soil, 266, 129-142, doi:10.1007/s11104-005-0874-y, 2005b.

Pellegrino, A., Gozé, E., Lebon, E., and Wery, J.: A modelbased diagnosis tool to evaluate the water stress experienced by grapevine in field sites, European J. Agronomy, 25, 49-59, doi:10.1016/j.eja.2006.03.003, 2006.

Prieto, I., Armas, C., and Pugnaire, F. I.: Water release through plant roots: new insights into its consequences at the plant and ecosystem level, New Phytologist, 193, 830-841, doi:10.1111/j.14698137.2011.04039.x, 2012.

Revil, A., Cathles, L. M., Losh, S., and Nunn, J. A.: Electrical conductivity in shaly sands with geophysical applications, J. Geophys. Res., 103, 23925, doi:10.1029/98JB02125, 1998.

Revil, A., Linde, N., Cerepi, A., Jougnot, D., Matthai, S., and Finsterle, S.: Electrokinetic coupling in unsaturated porous media, J. Coll. Interface Sci., 313, 315-327, doi:10.1016/j.jcis.2007.03.037, 2007.

Richards, L. A. and Wadleigh, C. H.: Soil water and plant growth, in: Soil physical conditions and plant growth, Volume 2, edited by: Byron, T. S., p. 491, Academic Press, London UK, 1952. 
Richards, L. A. and Weaver, L. R.: Moisture retention by some irrigated soils as related to soil-moisture tension, J. Agric. Res., 69, 215-235, 1944.

Ritchie, J. T.: Water dynamics in the soil-plant-atmosphere system, Plant Soil, 58, 81-96, doi:10.1007/BF02180050, 1981.

Robinson, D. A., Campbell, C. S., Hopmans, J. W., Hornbuckle, B. K., Jones, S. B., Knight, R., Ogden, F., Selker, J., and Wendroth, O.: Soil moisture measurement for ecological and hydrological watershed - scale observatories: a review, Vadose Zone J., 7, 358-389, doi:10.2136/vzj2007.0143, 2008.

Rossi, R., Amato, M., Bitella, G., Bochicchio, R., Ferreira Gomes, J. J., Lovelli, S., Martorella, E., and Favale, P.: Electrical resistivity tomography as a non-destructive method for mapping root biomass in an orchard, European J. Soil Sci., 62, 206-215, doi:10.1111/j.1365-2389.2010.01329.x, 2011.

Sadras, V. O. and Schultz, H. R.: Grapevine, in: Crop yield response to water, edited by: Steduto, P., Hsiao, T., Fereres, E., and Raes, D., p. 501, FAO, Rome, Italy, 2012.

Samouelian, A., Cousin, I., Tabbagh, A., Bruand, A., and Richard, G.: Electrical resistivity survey in soil science: a review, Soil Tillage Res., 83, 173-193, doi:10.1016/j.still.2004.10.004, 2005.

Schultz, H. R. and Matthews, M. A.: Resistance to Water Transport in Shoots of Vitis vinifera L., Plant Physiology, 88, 718-724, doi:10.1104/pp.88.3.718, 1988.

Schultz, H. R. and Stoll, M.: Some critical issues in environmental physiology of grapevines : future challenges and current limitations, Aust. J. Grape Wine Res., 16, 4-24, doi:10.1111/j.17550238.2009.00074.x, 2010.

Schwartz, B. F., Schreiber, M. E., and Yan, T.: Quantifying fieldscale soil moisture using electrical resistivity imaging, J. Hydrol., 362, 234-246, doi:10.1016/j.jhydrol.2008.08.027, 2008.

Seguin, G.: Alimentation en eau de la vigne dans des sols du HautMédoc, Connaissance Vigne Vin, 2, 23-34, 1969.

Seguin, G.: Alimentation en eau de la vigne et composition chimique des mouts dans les grand crus du Médoc. Phénomènes de regulation, Connaissance Vigne Vin, 9, 23-34, 1975.

Shah, P. H. and Singh, D. N.: Generalized Archie's law for estimation of soil electrical conductivity, J. ASTM Int., 2, 1-20, 2005.

Sinclair, T. R., Holbrook, N. M., and Zwieniecki, M. A.: Daily transpiration rates of woody species on drying soil, Tree Physiology, 25, 1469-1472, 2005.

Smart, D. R., Carlisle, E., Goebel, M., and Núñez, B. A.: Transverse hydraulic redistribution by a grapevine, Plant, Cell Environ., 28, 157-166, doi:10.1111/j.1365-3040.2004.01254.x, 2005.

Srayeddin, I. and Doussan, C.: Estimation of the spatial variability of root water uptake of maize and sorghum at the field scale by electrical resistivity tomography, Plant Soil, 319, 185-207, doi:10.1007/s11104-008-9860-5, 2009.

Stoll, M., Loveys, B., and Dry, P.: Hormonal changes induced by partial rootzone drying of irrigated grapevine, J. Exp. Botany, 51, 1627-1634, 2000.

Storchi, P., Constantini, E. A. C., and Buceli, P.: The influence of climate and soil on viticultural and enological parameters of Sangiovese grapevines under non-irrigated conditions, Acta Horticulturae, 689, 333-340, 2005.

Tabbagh, A., Dabas, M., Hesse, A., and Panissod, C.: Soil resistivity: a non-invasive tool to map soil structure horizonation, Geoderma, 97, 393-404, 2000.
Tarolli, P., Sofia, G., Calligaro, S., Prosdocimi, M., Preti, F., and Dalla Fontana, G.: Vineyards in terraced landscapes: new opportunities from Lidar data, Land Degradation Develop., 26, 92 102, 2015.

Tetegan, M., Pasquier, C., Besson, A., Nicoullaud, B., Bouthier, A., Bourennane, H., Desbourdes, C., King, D., and Cousin, I.: Field-scale estimation of the volume percentage of rock fragments in stony soils by electrical resistivity, Catena, 92, 67-74, doi:10.1016/j.catena.2011.09.005, 2012.

Tomasi, D., Gaiotti, F., and Jones, G. V.: The power of the terroir: the case study of Prosecco wine, Springer Basel, 2013.

Tramontini, S., Leeuwen, C., Domec, J.-C., Destrac-Irvine, A., Basteau, C., Vitali, M., Mosbach-Schulz, O., and Lovisolo, C.: Impact of soil texture and water availability on the hydraulic control of plant and grape-berry development, Plant Soil, 368, 215230, doi:10.1007/s11104-012-1507-x, 2012.

Triantafilis, J. and Lesch, S. M.: Mapping clay content variation using electromagnetic induction techniques, Comput. Electronics Agric., 46, 203-237, doi:10.1016/j.compag.2004.11.006, 2005.

van Leeuwen, C.: Terroir: the effect of the physical environment on vine growth, grape ripening and wine sensory attributes, in: Managing Wine Quality. Volume 1: Viticulture and wine quality, edited by: Reynolds, A., chap. 9, p. 624, Woodhead Publishing, Cambridge, UK, 1 edn., available at: http://www.sciencedirect. com/science/book/9781845694845 (last access date: 12 March 2015), 2010.

van Leeuwen, C. and Seguin, G.: The concept of terroir in viticulture, J. Wine Res., 17, 1-10, doi:10.1080/09571260600633135, 2006.

van Leeuwen, C., Friant, P., Choné, X., Tregoat, O., Koundouras, S., and Dubourdieu, D.: Influence of climate, soil, and cultivar on terroir, Am. J. Enol. Viticulture, 55, 207-217, 2004.

van Leeuwen, C., Tregoat, O., and Choné, X.: Vine water status is a key factor in grape ripening and vintage quality for red bordeaux wine. How can it be assessed for vineyard management purposes?, J. Int. Sci. Vigne Vin, 43, 121-134, 2009.

van Leeuwen, C., Pieri, P., and Vivin, P.: Comparison of three operational tools for the assessment of vine water status: stem water potential, carbon isotope discrimination measured on grape sugar and water balance, in: Methodologies and Results in Grapevine Research, edited by: Delrot, S., Medrano, H., Or, E., Bavaresco, L., and Grando, S., chap. 7, pp. 87-106, Springer Netherlands, 1 edn., doi:10.1007/978-90-481-9283-0, 2010.

Veihmeyer, F. J. and Hendrickson, A. H.: Soil moisture in relation to plant growth, Annu. Rev. Plant Physiology, 1, 285-305, 1950.

Waxman, M. H. and Smits, L. J. M.: Electrical conductivities in oil-bearing shaly sands, Soc. Pet. Eng. J., 8, 107-122, doi:10.2118/1863-A, 1968.

Werban, U., Attia al Hagrey, S., and Rabbel, W.: Monitoring of root-zone water content in the laboratory by $2 \mathrm{D}$ geoelectrical tomography, J. Plant Nut. Soil Sci., 171, 927-935, doi:10.1002/jpln.200700145, 2008.

Winsauer, W. O., Shearin, H. M., Masson, P. H., and Williams, M.: Resistivity of brine-saturated sands in relation to pore geometry, AAPG B., 36, 253-277, 1952. 
Zsófi, Z., Gál, L., Szilágyi, Z., Szũcs, E., Marschall, M., Nagy, Z., and Bálo, B.: Use of stomatal conductance and pre-dawn water potential to classify terroir for the grape variety Kékfrankos, Aust. J. Grape Wine Res., 15, 36-47, doi:10.1111/j.17550238.2008.00036.x, 2009. 